\title{
Expression of CEA, CA125, CA19-9 and human milk fat globule membrane antigen in ovarian tumours
}

\author{
FIONA MACDONALD, ROSALIND BIRD, HAZEL STOKES, BARBARA RUSSELL, \\ J CROCKER*
}

From the Surgical Immunology Unit, Queen Elizabeth Hospital, Birmingham, and the *Department of Histopathology, East Birmingham Hospital, Bordesley Green, Birmingham

SUMMARY The expression of five different antigens in ovarian tumours was studied by means of an immunohistochemical test with anti-CEA, HMFG1 and HMFG2, NS19-9 and OC125 antibodies. Considerable variation was noted not only between different histological types and between tumours of one type but also between areas in a single tumour. HMFG1 and HMFG2 were the most reactive of all the antibodies; NS19-9 and OC125 were expressed by different populations of cells. It is concluded that specific combinations of antibodies are more effective both for the monitoring of ovarian cancer as well as for immunodiagnosis and treatment, than any single one used.

Ovarian tumours are the most common cause of death from gynaecological cancers; although cure rates are high if the cancer is detected early, diagnosis is often made when the disease has spread throughout the abdomen. A specific, sensitive tumour marker for the monitoring of disease, which would also be a potential target antigen for immunotherapy and diagnosis would therefore be of value.

Serum concentrations of carcinoembryonic antigen (CEA), ${ }^{12}$ human chorionic gonadotrophin and $\alpha$ fetoprotein (hCG, AFP) ${ }^{3}$ have been used to monitor treatment and the incidence of recurrence in patients with specific types of ovarian cancer. CA125 has recently been shown to be particularly valuable for monitoring treatment in non-mucinous epithelial tumours. ${ }^{45} \mathrm{CA1} 19-9$ is a monosialoganglioside originally isolated from a colonic tumour cell line but has also been used in combination with CA 125 as a marker for serological monitoring of ovarian cancer. ${ }^{6}$ Radiolabelled anti-CEA, and HMFG 1 and 2 have been used to localise ovarian tumours ${ }^{8}$ and are now beginning to be used in treatment regimens. ${ }^{9}$

The pathology of ovarian tumours, however, is complex and a wide range of histological types have been identified..$^{10}$ No single antibody reacts with all histological types nor even with all tumours in one group. Combinations of antibodies may therefore prove more effective for serological monitoring as well as the radioimmunolocalisation and treatment of tumours. $^{61112}$ Few studies giving cross sectional data on the expression of the different tumour associated

Accepted for publication 14 October 1987 antigens, commonly used for diagnosis of ovarian cancers, have been published. In this study the expression of these markers has therefore been examined on a wide range of histological types of ovarian tumours.

\section{Material and methods}

Tissue sections ( $3 \mu \mathrm{m}$ thick) were obtained from formalin fixed paraffin embedded tissues. Blocks were obtained from the common ovarian epithelial neoplasms, germ cell tumours, and from sex cord stromal tumours. Sections from one to eight blocks were obtained from each tumour. Diagnosis had been made from sections stained with haematoxylin and eosin at the time of surgery but was also reviewed by one of us (JC) when the study began.

HMFG 1 and 2 were kindly provided by Oxoid Ltd, Bedford; NS19-9 and OC 125 were purchased in kit form (CIS UK, London); and 11-285-14 (anti-CEA) was raised in our unit in collaboration with Eli Lilly Ltd, Windlesham, Surrey and has been extensively characterised. ${ }^{13-16}$

An indirect immuoperoxidase technique was used in conjunction with 11-285-14, HMFG 1 and 2 antibodies, with 3,3 diamino benzidine as the substrate. ${ }^{17} 11-285-14$ was used at a concentration of $3 \mu \mathrm{g}$ protein $/ \mathrm{ml}, \mathrm{HMFG} 1$ was used at $0.66 \mu \mathrm{g}$ protein $/ \mathrm{ml}$, and $\mathrm{HMFG} 2$ was used at $10 \mu \mathrm{g}$ protein $/ \mathrm{ml}$. An avidinbiotin technique was used with NS19-9 and OC 125, as detailed by the suppliers of these antibodies (CIS UK). A preliminary study showed that any tissue negative with HMFG 1 and 2 and 11-285-14 by the indirect immunoperoxidase technique remained 
Table 1 Antigen expression in epithelial ovarian tumours

\begin{tabular}{|c|c|c|c|c|c|}
\hline \multirow[b]{3}{*}{ Histology } & \multicolumn{5}{|l|}{ Antibodies } \\
\hline & $11-285-14$ & $H M F G I$ & $H M F G 2$ & NSI9-9 & OCI25 \\
\hline & \multicolumn{5}{|c|}{$\begin{array}{l}\text { (No positive/No } \\
\text { tested) }\end{array}$} \\
\hline $\begin{array}{l}\text { Serous cystadenocarcinoma } \\
\text { Serous cystadenoma } \\
\text { Mucinous cystadenocarcinoma } \\
\text { Mucinous cystadenoma } \\
\text { Endometroid } \\
\text { Clear cell } \\
\text { Brenner } \\
\text { Undifferentiated } \\
\text { Total (not including adenomas) }\end{array}$ & $\begin{array}{l}5 / 16 \\
0 / 4 \\
7 / 8 \\
0 / 3 \\
1 / 5 \\
0 / 5 \\
0 / 3 \\
0 / 1 \\
13 / 38\end{array}$ & $\begin{array}{l}14 / 16 \\
4 / 4 \\
8 / 8 \\
2 / 3 \\
5 / 5 \\
5 / 5 \\
3 / 3 \\
0 / 1 \\
35 / 38\end{array}$ & $\begin{array}{l}12 / 16 \\
4 / 4 \\
6 / 8 \\
3 / 3 \\
5 / 5 \\
5 / 5 \\
2 / 3 \\
0 / 1 \\
30 / 38\end{array}$ & $\begin{array}{l}11 / 16 \\
2 / 4 \\
6 / 8 \\
2 / 3 \\
1 / 2 \\
0 / 3 \\
1 / 3 \\
0 / 1 \\
19 / 38\end{array}$ & $\begin{array}{l}12 / 16 \\
1 / 4 \\
2 / 8 \\
0 / 3 \\
3 / 5 \\
2 / 5 \\
0 / 3 \\
0 / 1 \\
19 / 38\end{array}$ \\
\hline
\end{tabular}

negative if the more sensitive avidin-biotin technique was used.

A colonic tumour reactive with 11-285-14, HMFG 1 and 2, and NS19-9, and an ovarian tumour reactive with $\mathrm{OC} 125$ were included as positive controls in each batch of tests. Primary antibody was replaced by control ascites (Bethesda Research Laboratories (UK) Ltd, Cambridge) on a second section from each tissue to act as a negative control. All sections were scored independently by two observers. Slides were considered to be positive if over $5 \%$ of tumour cells were stained. If more than one block was available and results varied between blocks, the result recorded was that of the positive block.

\section{Results}

Expression of all the antigens studied varied considerably between blocks from individual tumours. In the most extreme example sections from one block of a mucinous adenocarcinoma were negative with HMFG 1 and 2; those from another block showed intense staining with the same antibodies in over $50 \%$ of tumour cells.

$11-285-14$ antibody reacted with $34 \%$ of the "common" epithelial tumours-primarily the mucinous cystadenocarcinomas. Neither serous nor mucinous cyst adenomas were reactive with this antibody (table 1). Both HMFG 1 and 2 were positive in most epithelial tumours. Neither antibody, however, was capable of differentiating between malignant and benign neoplasms (table 1). In addition, they reacted with normal areas of tissue-in particular, normal endometrial epithelium and fallopian tube epithelium (fig 1). Serous tumours reacted with both OC125 and NS19-9. Mucinous tumours were mainly positive with NS19-9 but two cases also reacted with OC125.

The total number of germ cell and sex cord stromal tumours examined was small because of their relative rarity in comparison with the epithelial tumours. Once again, HMFG 1 and 2 showed the highest level of staining of all the antibodies (table 2).

In tumours metastatic to the ovary HMFG 1 and 2 were positive in all five cases tested, regardless of the site of the primary. 11-285-14 was negative in two of three ovarian secondaries, despite their colonic origin. OC125 did not react with any ovarian secondaries whose primary was of colonic origin (table 3). Staining patterns of a gastric primary and its secondary Krukenberg tumour are shown in table 4 . The antigen expression of the secondary was not necessarily a reflection of the expression of the primary.

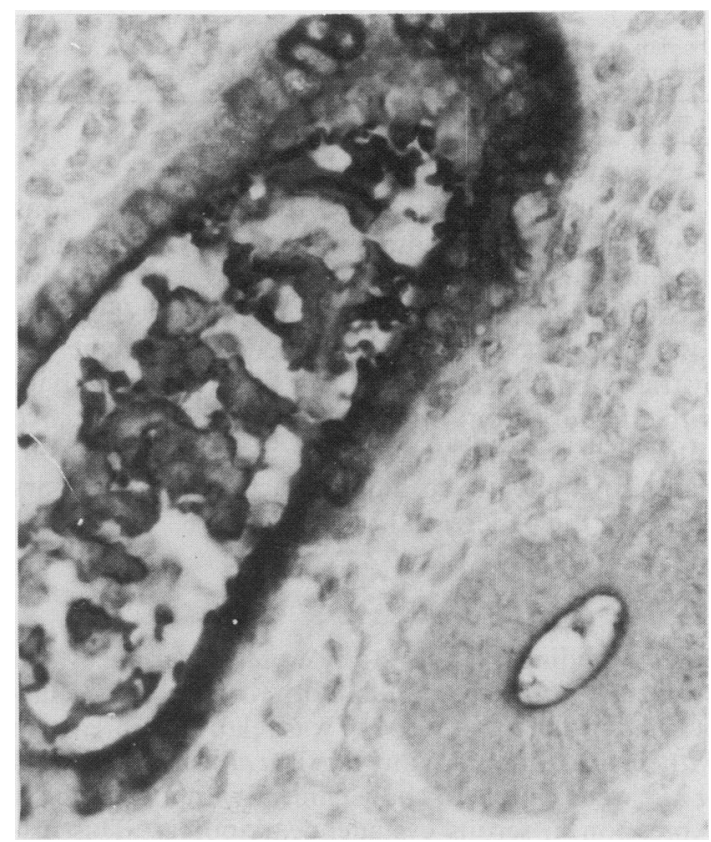

Fig 1 Reactivity of normal endometrium with HMFG1. 
Table 2 Antigen expression in germ cell and sex cord stromal tumours

\begin{tabular}{llllll}
\hline & \multicolumn{2}{l}{ Antibodies } & & & \\
\cline { 2 - 6 } Histology & $11-285-14$ & HMFGI & HMFG2 & NSI9-9 & OC125 \\
\hline Dysgerminoma (1) & $1 / 1$ & $1 / 1$ & $1 / 1$ & $1 / 1$ & $1 / 1$ \\
Malignant teratoma(1) & $0 / 1$ & $1 / 1$ & $1 / 1$ & $1 / 1$ & $1 / 1$ \\
Benign teratoma (5) & $2 / 5$ & $5 / 5$ & $4 / 5$ & $2 / 5$ & $2 / 5$ \\
Total (7) & $3 / 7$ & $7 / 7$ & $6 / 7$ & $4 / 7$ & $3 / 7$ \\
Granulosa cell (4) & $1 / 4$ & $2 / 4$ & $1 / 4$ & $0 / 4$ & $1 / 4$ \\
Thecoma (4) & $0 / 4$ & $1 / 4$ & $1 / 4$ & $0 / 4$ & $0 / 2$ \\
Fibroma (2) & $0 / 2$ & $0 / 2$ & $0 / 2$ & $0 / 10$ & $1 / 10$ \\
Total (10) & $1 / 10$ & $3 / 10$ & $2 / 10$ & 0 & 0 \\
\hline
\end{tabular}

Table 3 Antigen expression in tumours metastatic to ovary

\begin{tabular}{llll}
\hline & \multicolumn{2}{l}{ Site of primary tumour } \\
\cline { 2 - 4 } Antibody & Colon & Stomach & Unknown \\
\hline $11-285-14$ & $1 / 3$ & $1 / 1$ & $1 / 1$ \\
HMFG1 & $3 / 3$ & $1 / 1$ & $1 / 1$ \\
HMFG2 & $3 / 3$ & $1 / 1$ & $1 / 1$ \\
NS19-9 & $2 / 3$ & $0 / 1$ & $0 / 1$ \\
OC125 & $0 / 3$ & $1 / 1$ & $1 / 1$ \\
\hline
\end{tabular}

Table 4 Comparison of staining in primary and ovarian secondary tumours

\begin{tabular}{llllll}
\hline Tumour & $11-285-14$ & HMFG1 & HMFG2 & NS19-9 & OC125 \\
\hline $\begin{array}{l}\text { Gastric } \\
\text { primary }\end{array}++$ & + & ++++ & +++ & Negative \\
$\begin{array}{l}\text { Ovarian } \\
\text { secondary }+++\end{array}+++$ & + & Negative & +++ \\
\hline$+=$ weak staining (5-10\%) of cells; \\
$++++=$ intense staining of nearly all cells.
\end{tabular}

The staining pattern of NS19-9 and OC125 was shown to be complementary not only between primary tumours and their metastases (table 4) but also between different areas of the same primary (fig 2).

None of the antibodies studied was specific for ovarian tumours, as was evident from their reactivity with tumours from other sites (table 5). Of the five antibodies examined, OC125 was the most specific but was also found to be highly reactive with tumours arising in the pancreas.

\section{Discussion}

Several findings in this study were at variance with previously published results. Both $\mathrm{Kremer}^{18}$ and Charpin et $\mathrm{l}^{19}$ found that NS19-9 was relatively unreactive with serous tumours. Van Nagell et al ' and Marchand et $a l^{20}$ were unable to show clinically important CEA expression in serous cystadenocarcinomas. This discrepancy with our results may have been caused by the number of blocks examined from individual tumours in our study. As shown, examination of only one block does not always give a reliable indication of antigen expression. Secondly, a number of different antibodies to CEA have been used by different groups. These almost certainly recognise different epitopes on the molecule, which may result in differences in the detection rate of the antigen.

Two colorectal tumours metastatic to the ovary were negative for CEA. This suggests that expression of CEA cannot be used to differentiate between primary ovarian tumours and colorectal metastases. This result is in line with recent findings which suggest that many colorectal metastases are negative for CEA despite the high expression of this marker in the primary tumours (unpublished observations).

$\mathrm{OC} 125$ has been considered to be a marker of nonmucinous tumours. In this study two of eight mucinous tumours were found to be positive-a finding consistent with raised serum concentrations in some patients with mucinous tumours. The detection of CA125 in these tumours may be a reflection of the number of blocks examined. Secondly, it may be related to the fixation methods used. Studies in our laboratory have shown that some fixation methods affect the ability to detect CA125 and showed that pretreatment with protease is necessary to show the antigen (unpublished observations).

The extent of antigenic heterogeneity shown in this study confirms the value of using more than one antibody for tumour imaging and treatment. The antibodies to HMFG reacted with most tumours in the study. If only one antibody is to be used, one of these would be the most effective. Several studies have shown this to be the case. ${ }^{89}$ Their reactivity with normal tissues and their inability to differentiate between benign and malignant tissues, however, may limit their use. Refinement of the antibodies, particularly if they can be directed against a protein epitope of the molecule would greatly increase their value. 


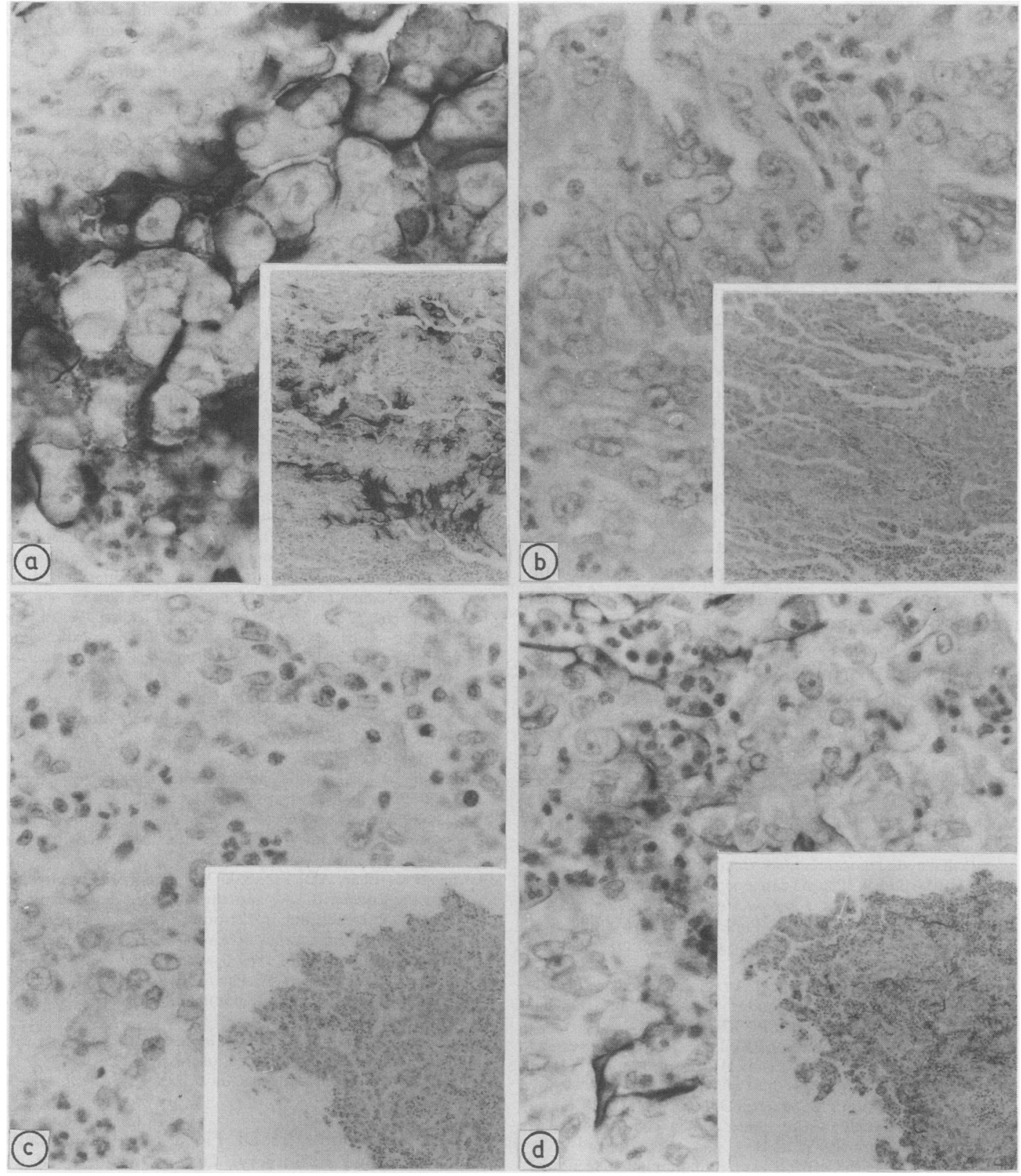

Fig 2 Expression of CA19-9 and CA125 in two consecutive sections from moderately differentiated serous adenocarcinoma showing expression of two markers by different populations of cells.

(a) Section 1, area 1, positive staining with NS19-9; (b) section 2, area 1, negative reaction with OC125; (c) section 1, area 2, negative reaction with NS19-9; (d) section 2, area 2, positive staining with OC125. 
Table 5 Antigen expression in non-ovarian tumours

\begin{tabular}{llllll}
\hline \multirow{5}{*}{ Antibody } & & & \\
\cline { 2 - 6 } & $11-285-14$ & HMFG1 & HMFG2 & NS19-9 & OC125 \\
\hline Colorectal & $20 / 20$ & $13 / 20$ & $16 / 20$ & $0 / 5$ & \\
Gastric & $208 / 226$ & $5 / 5$ & $4 / 5$ & $5 / 5$ & $0 / 5$ \\
Pancreatic & $23 / 30$ & $8 / 8$ & $8 / 8$ & $5 / 5$ & $5 / 5$ \\
Lung & $4 / 5$ & $5 / 5$ & $5 / 5$ & $3 / 5$ & $0 / 5$ \\
Breast & $1 / 5$ & $5 / 5$ & $5 / 5$ & $0 / 5$ & $0 / 5$ \\
\hline
\end{tabular}

A combination of NS19-9 and OC125 has been used for serological monitoring of ovarian cancer. ${ }^{621}$ In one study changes in serial serum concentrations of these markers in response to chemotherapy were found, and it was suggested that this might be the result of differential secretory activity of cells. We have shown that the two markers are not only expressed by a different subset of tumours of varying histological type but by different cells within the same tumours. Further studies are under way to investigate whether either of these markers identifies a group of cells with either higher metastatic potential or of changed resistance to chemotherapy. In the meantime this combination seems to be useful for both serological monitoring and as a carrier of radioisotopes or drugs for the treatment of ovarian cancers.

Many thanks to Lorraine May for her typing of the manuscript and to Peter Canney for his helpful comments.

\section{References}

1 Van Nagell JR, Donaldson ES, Gay EC, Sharkey RM, Rayburn P, Goldenberg DM. Carcinoembryonic antigen in ovarian epithelial cystadenocarcinomas. Cancer 1978;41:2335-40.

2 Stall KE, Martin EW. Plasma carcinoembyronic antigen levels in ovarian cancer patients. $J$ Reprod Med 1981;26:73-9.

3 Donaldson ES, Van Nagell JR, Pursell S, et al. Multiple biochemical markers in patients with gynecologic malignancies. Cancer 1980;45:948-53.

4 Bast RC, Klug TL, St John E, et al. A radioimmunoassay using a monoclonal antibody to monitor the course of epithelial ovarian cancer. N Engl J Med 1983;309:883-7.

5 Canney PA, Moore M, Wilkinson PM, James RD. Ovarian cancer antigen CA125: a prospective clinical assessment of its role as a tumour marker. Br J Cancer 1984;50:765-9.

6 Canney PA, Wilkinson PM, James RD, Moore M. CA19-9 as a marker for ovarian cancer: alone and in comparison with CA125. Br J Cancer 1985;52:131-3.

7 Van Nagell JR, Kim E, Casper S, et al. Radioimmunodetection of primary and metastatic ovarian cancer using radiolabelled antibodies to carcinoembryonic antigen. Cancer Res 1980;40:502-6.

8 Epenetos AA, Mather S, Granowska M, et al. Targetting of iodine-123 labelled tumour-associated monoclonal antibodies to ovarian, breast and gastro-intestinal tumours. Lancet 1982;ii:999-1004.

9 Hammersmith Oncology Group and Imperial Cancer Research Fund. Antibody guided irradiation of malignant lesions: three cases illustrating a new method of treatment. Lancet 1984;i:1441-3.

10 Serov SV, Sculley RE, Sobin LH, eds. Histological typing of ovarian tumours. International histological classification of tumours No 9. Geneva: WHO, World Health Organisation, 1973.

11 Dhokia B, Canney PA, Pectasidos D, et al. A new immunoassay using monoclonal antibodies HMFG1 and HMFG2 together with an existing marker CA125 for the serological detection and management of epithelial ovarian cancer. $\mathrm{Br} J$ Cancer 1986;54:891-5.

12 Gaffar AA, Pant KD, Shochat D, Bennett SJ, Goldenberg DM. Experimental studies of tumour immunodetection using antibody mixtures against carcinoembryonic antigen (CEA)and colon-specific antigen (CSAp). Int J Cancer 1981;27:101-5.

13 Corvalan JRF, Axton CA, Brandon DR, Smith W, Woodhouse C. Classification of anti-CEA monoclonal antibodies. Protides of Biological Fluids 1983;31:921-4.

14 Crowson MC, Hockey MS, Newman J, Stokes HJ, Macdonald F, Fielding JWL. An immunocytochemical study of CEA in colorectal tumours and their metastases. Br J Surg 1984;71:376.

15 Hockey MS, Stokes HJ, Thompson $\mathrm{H}$, et al. Carcinoembryonic antigen (CEA) expression and heterogeneity in primary and autologous metastatic gastric tumours demonstrated by a monoclonal antibody. Br J Cancer 1984;49:129-33.

16 Allum WHA, Stokes HJ, Macdonald F, Fielding JWL. Demonstration of carcinoembryonic antigen (CEA) expression in normal, chronically inflamed and malignant pancreatic tissue by immunohistochemistry. J Clin Pathol 1986;39:610-14.

17 Ford CHJ, Stokes HJ, Newman CE. Carcinoembryonic antigen and prognosis after radical surgery for lung cancer. Immunocytochemical localisation and serum levels. $\mathrm{Br} J$ Cancer 1981;44:145-9.

18 Kremer $M$. Diagnostic immunohistochemique des tumeurs ovariennes avec anticorps monoclonal OC125. In: Chatal JF, Douis M, eds. Monoclonal antibodies in oncology: clinical applications. Paris: Nouvelles Editions Medicales Françaises, 1984:39-41.

19 Chapin C, Bhan AD, Zurawski VR, Sculley RE. Carcinoembryonic antigen (CEA) and carbohydrate determinant 19-9 (CA 19-9) localisation in 121 primary and metastatic ovarian tumours: an immunohistochemical study with the use of monoclonal antibodies. Int J Gynecol Pathol 1982;1:231-45.

20 Marchand A, Fenoglio CM, Pascal R, Richart RM, Bennett S. Carcinoembryonic antigen in human ovarian neoplasms. Cancer Res 1975;35:3807-10.

21 Bast RC, Klug TL, Schaetzl E, et al. Monitoring human ovarian carcinoma with a combination of CA125, CA19-9 and carcinoembryonic antigen. Am J Obstet Gynecol 1984;149: 553-9.

Requests for reprints to: Dr Fiona Macdonald, Barling Ratcliffe Fellow in Surgery, Queen Elizabeth Medical Centre, Edgbaston, Birmingham B15 2TH, England. 